\title{
Pronominal in Assamese and Bengali Language: A Comparative Analysis
}

Dr Archita Bhattacharyya ${ }^{+}$

\section{Abstract}

Out of the several modern Indo-Aryan languages that evolved in the eastern part of India, Assamese and Bengali are the two most prominent ones. Though both these two languages reached their respective present existence after passing through different phases of development, yet their roots are the same. Therefore, between both languages, there are many similarities even though both have evolved in distinctly different geographical areas, and there exist distinct differences between them. The differences not only create the distinction between them but also express their individuality too. In both, the languages, pronoun and pronominal have occupied an important role in the discussion of morphology. Along with pronoun, the use of various pronominal which have evolved from the same root has flourished in both the languages. In this regard, both similarities and differences could be noticed in these two languages. Therefore, to identify the co-relation as well as the linguistic characteristics of both languages, the comparative analysis is the only way out. In this study, an attempt is made to focus on how the pronominal of both languages are used to identify the similarities and differences between the two languages.

Keywords: Assamese; Bengali; Morphology; Pronoun; Pronominal; Comparative Method; India

\footnotetext{
+ Independent Researcher, Email: ms.archita@gmail.com

(C) 2020 Bhattacharyya. This is an Open Access article distributed under the terms of the Creative Commons Attribution License (http://creativecommons.org/licenses/by/2.0), which permits unrestricted use, distribution, and reproduction in any medium, provided the original work is properly cited.
} 


\section{Introduction}

Assamese is the principal language of the State of Assam, and often regarded as the linguafranca for the North East of India (Goswami, 1982, p.3)_he other languages spoken in Assam belong to different language families, viz., Hindi, Bengali, Bhojpuri, Nepali, Sadri, of Neo IndoAryan family; Bodo, Karbi, Rabha, Mising, Tiwa, Dimasa, Deuri of Tibeto-Burman family; Turung, Khamti, Phake, Aiton of the Tai group of SinoTibetan family; Chautal, Munda, Kurukh, Vili, Shabar of Austro-Asiatic family; Tamil, Telegu, Malayalam and so on of Dravidian family (Bhattacharyya, 2013). The easternmost member of the Indo-European family is the Assamese language. "Assamese is an Indo-Aryan language [that] originated from the Vedic dialects, and therefore, a sister of all the northern Indian languages of the country. But the exact nature of the origin and growth of the language is not very clear yet. It is supposed that like other Aryan languages Assamese was also born from Apabhramsa dialects developed from Magadhai Prakrit of the eastern group of Sanskritik languages" (Goswami, 1982, p. 3). Assamese is the anglicised name of Asamiya which is the official language of Assam declared by the Constitution of India. It is spoken in other states like Nagaland and Arunachal Pradesh in the form of creole and pidgin (Rabha Hakacham, 2009, p.1). As per the report of Census of India 2011, Assamese is the mother tongue of 1,53,11,351 persons. (Office of the Registrar General \& Census Commissioner, India, 2011, Statement-1)

Similarly, Bengali is also an Indo-Aryan language of the eastern Indian subcontinent, evolved from the Magadhi Prakrit, Pāli and Sanskrit languages. Bengali is native to the region of eastern South Asia known as Bengal, which comprises present-day Bangladesh and the Indian state of West Bengal. Bengali is the primary language spoken in Bangladesh and is the second most widely spoken language in India (Chatterji, 1970; Choudhury, 2012; Majumdar, 1980, Sengupta, 2013, Goyal, 2020). As per the report of the Census of India (2011), Bengali is the mother tongue of as many as 9,72,37,669 persons. (Office of the Registrar General \& Census Commissioner, India, 2011, Statement-1).

As both the Assamese and Bengali are derived from the world's largest language family, that is, Indo-European language family, that is why in the discussion of linguistic studies various similarities have been seen between both the languages.

From the point of view of comparative as well as historical studies among the various elements of language, such as phonology, ${ }^{1}$ morphology, ${ }^{2}$ syntax, ${ }^{3}$ and semantics, ${ }^{4}$ the most important among them is morphology. According to Bloomfield, "By the morphology of a language, we mean the constructions in which bound forms appear among the constituents. By definition, the resultant forms are either bound forms or words, but never phrases. Accordingly, we may say that morphology includes the constructions of words and part of words, while syntax includes the constructions of phrases" (Bloomfield, 1963, p. 217). Nida defines morphology as the study of morphemes and their arrangement in forming words (Nida, 1949, p. 1). The main subject matter in the study of morphology is morphemes. Morphology alludes to the utilisation of or the investigation of morphemes, the parts of words that pass on significance. The exact part of morphology differs with every dialect, contingent upon the word arrangement forms utilised as a part of every dialect (Akbulut, 2017, p. 12). Morphemes can be usually described as a smallest meaningful unit in the structure of the language. According to Laurie Bauer, the basic units of

\footnotetext{
${ }^{1}$ Phonology is the study of the structured system of sounds of a language (Bhattacharya, 2008, p. 97).

${ }^{2}$ Morphology is the study of morphemes and their arrangement in forming words (Nida, 1949, p. 1).

${ }^{3}$ Syntax is the study of sentence structure and the rules which govern what is grammatical and what is not (Morshed Manzur, 2007, p. 334).

${ }^{4}$ Semantics is the study of the meaning of a word (Hazarika, 2006, p. 41).
} 
analysis recognised in the morphology are morphemes (Bauer, 1983, p. 13). There are two types of morphemes, viz; free morphemes and bound morphemes. Generally, bound morphemes are called as affix. According to their place, bound morphemes/affix can be categorised in three parts, viz., prefix, ${ }^{5}$ suffix ${ }^{6}$ and infix. ${ }^{7}$ An affix can further be sub-divided into two parts, viz., derivative affix and inflective affix. In the study of morphology, another vital subject is root morphemes. The root is the nucleus of all morphological constructions. It is the most critical gravitational centre that attracts the peripheral affixes around (Goswami, 1982 , p. 157). Generally, a word is formed by way of connecting affix with the root morphemes. The word which is used in the construction of a meaningful sentence is called an inflected word. Such inflected words can be divided into four main parts. Such four parts are noun, adjective, pronoun and verb. The importance of all these inflected words is numerous in the discussion of morphology.

In morphology, pronoun plays an important role. A pronoun is a word used in place of a noun to avoid its repetition (Bhanot and Martin, 2013, p. 57). Morphologically pronouns belong to a subclass of nouns: both share the same set of case inflexions, but differ in syntax and derivation. Like the nouns, the pronouns also have prefixes and suffixes as peripheral derivatives, but reduplication and compounding are lacking in the latter (Goswami, 1982, p. 233). The word constructed from the root of pronoun is called pronominal. Pronominal is used not only in pronoun, but it is also applicable in noun and verb (Rabha Hakacham, 2000, p. 142). In the construction of an indeclinable word which is used as an adverb, the root of pronominal played an important role. Therefore, in the discussion of morphology, the importance of the use of pronominal is as much vital as that of pronoun.

Pronominal is widely used in the construction of a sentence in Assamese. The pronominal roots, unlike those of the nouns and verbs, are limited in number and different in derivational nature. In the root of various pronominal morphemes are added as prefix and suffix. Generally, a pronoun can be divided into various parts. How prefixes and suffixes are used in the root of pronominal in Assamese is shown in Table 1.

Table1: Relating to Prefixes and Suffixes used in Assamsese Root of Pronominal

\begin{tabular}{|ll|}
\hline Prefix & Suffix \\
\hline i-/e-/a- & -on \\
\hline $\mathrm{t}-$ & $-\mathrm{h}$ \\
\hline $\mathrm{x}-$ & $-\mathrm{o}$ \\
\hline $\mathrm{z}-$ & $-\mathrm{ba}$ \\
\hline $\mathrm{k}-$ & $-\mathrm{su}$ \\
\hline Source: Author & \\
\hline
\end{tabular}

On the basis of the Table 1, as per the meaning created. Sometimes these pronominals are used of morpheme, various pronominals can be as an adjective or as an adverb. On the basis of created from the root of pronoun. It is pertinent to mention that in the Assamese language along with the root of pronoun by adding a various suffix like person, inanimate, place, time, quantity, similarities, several pronominals are

\footnotetext{
${ }^{5} \mathrm{~A}$ prefix is a morpheme which is added to the beginning of a root/free morpheme in order to form a different word (Bhattacharya, 2012, p. 275).

${ }^{6} \mathrm{~A}$ suffix is a morpheme which is added to the end of a root/free morpheme in order to form a different word (Hazarika, 2006, p.89).
}

\footnotetext{
${ }^{7}$ An infix is a morpheme which inserted into the root/free morpheme with which it is associated (Hazarika, 2006, p.89).
}

- Demonstrative Pronominal

- Relative Pronominal classified into four parts: 
- Interrogative and Indefinite Pronominal

- Miscellaneous Pronominal

These four parts are discussed in the discussion section.
As in Assamese, the use of pronominal in Bengali is also noticeable. In Bengali, the pronominal prefixes and suffixes are grouped according to their distribution as shown in Table 2.

\begin{tabular}{|l|l|}
\hline \multicolumn{2}{|l|}{ Table 2: Relating to Prefixes and Suffixes used in Bengali Root of Pronominal } \\
\hline Prefix & Suffix \\
\hline e-ei- & -tha/-thy \\
\hline o-/oi-/a-/t- & -khan/-khane \\
\hline z-/ze-/zei- & -khon/-be \\
\hline k-/ke-/kon- & -t/-to \\
\hline Source: Author &
\end{tabular}

On the basis of Table 2 stated above, pronominal in the Bengali language is also classified into four parts:

- Demonstrative Pronominal

- Relative Pronominal

- Interrogative and Indefinite Pronominal

- Miscellaneous Pronominal

In this study, an attempt is made to identify the co-relation between Assamese and Bengali language by taking the pronominal as the main subject of discussion. On the basis of the classification of pronominal of both the languages, an endeavour is made to compare the similarities and dissimilarities between the said two languages with the help of theTable 1 and 2. The structure of the study is as follows: in the next section, the key methods adopted in the study has been discussed. Following this, in the discussion section, we critically analyse the study and finally, in the conclusion section, we have observed various characteristics common to each other and tried to discuss the findings.

\section{Methodology}

In this study, the comparative method has been chosen for discussing the use of pronominal in both Assamese and Bengali. A comparative study is a diachronic comparison of two or more linguistic systems to classify languages into families (Boruah, 2006, p.6). A comparative study is interested in establishing similarities or correspondences between languages. Language is dynamic. Therefore, with the change of time, place etc., change in a language is very common. The aspect of a comparative study of language is crucial so that the loss of co-relation may not happen due to the change of circumstances and others. It is to be stated that just to ascertain the co-relation as well as the characteristics of two languages which have arisen from a common root, the comparative study assumes great importance. It is pertinent to mention that the famous language family of the world is mainly discovered and classified on the basis of comparative and changing historical studies.

This study is mainly carried out on the basis of the comparative study of pronominal which is based on four classifications of pronominalDemonstrative Pronominal, Relative Pronominal, Interrogative and Indefinite Pronominal and Miscellaneous Pronominal. It is noteworthy to mention that in both the languages we find various dialects, but this study is solely based upon the standard language, which is mainly used in academic and official works etc. This present study is conducted after going through several books relating to linguistics of both the languages, dictionaries, and various research articles. Through this study, an effort is made to identify the similarities and dissimilarities observed on the aforesaid pronominal.

\section{Discussion}

On the basis of the aforementioned classification of pronominal, the present 
research is carried forward to identify the similarities and dissimilarities of both the languages.

\section{Demonstrative Pronominal}

Demonstrative pronominal indicates any object or living creature situated near or far in the distance. It can be singular or plural. These pronominals can work both as subjects as well as objects, usually describing places, things, time, animal and people.

\section{Similarities}

Regarding demonstrative pronominal, in both the languages two types of pronominals are found, that is, direct and indirect (Kakoti, 1972; Chatterji, 1970). In Assamese language, prefix like $e, i, a$ (from Table-1) are added in the root of direct demonstrative pronominal. In the Bengali language also prefix like $e$, ei (from Table-2) are added in the root of direct demonstrative pronominal to indicate time, place, object and similar things. From the root of direct demonstrative pronominal ' $e$ ', in Assamese, various pronominals like 'eitu' (this one), 'eikhini' (these one), 'eibilak' (these are), 'eibor' (these are) are used. These pronominals may be regarded as a near demonstrative. In Bengali too, various pronominals like 'eita' (this one), 'eigolo' (these are), 'eigoli' (these are), 'eisob' (these are), 'eisamasta' (these are) are used in a similar sense. In this context, the similarities of both languages may be observed.

eitu/eita:- In both languages, this pronominal is used to demonstrate any object lying in a nearby area.

In Assamese: - eitu:- eitu tumar kalam niki? [Is this your pen?]

In Bengali: - eita:- eita ki tumar kalam? [Is this your pen?]

In both the languages, pronominals like eikhini, eibilak, eibor / eigolo, eigoli, eisob, eisamasta are used to demonstrate one or more object lying in a nearby area.

In Assamese: - eikhini:- eikhini sob ekekhon baganore phul. [All these flowers are from the same garden]
In Bengali: - eigoli:- eigoli sob eke baganer phul. [All these flowers are from the same garden.]

In Assamese, pronominal like 'etiya' (this time), 'etiyao' (as yet) are used to demonstrate time. Similarly, in Bengali language, pronominal like 'ekhon', (this time) 'ekhono' (as yet) are used to demonstrate time.

In Assamese: - etiya: - Kono bostuei etiya sulabh nahai. [Nothing is cheaper nowadays.]

In Bengali:- ekhon:- Kono jinisei ekhon sulabh noy. [Nothing is cheaper nowadays.]

In Assamese:- etiyao:- Moi etiyao bhat khoa nai. [I have not yet taken my meal.]

In Bengali:- ekhono:- Ami ekhono bhat khainei. [I have not yet taken my meal.]

In Assamese language, pronominal like 'ene' (such like), 'enekoi' (in this manner), 'enekua' (in this manner) are used to demonstrate similarities with any object or thing. In a similar context pronominal like 'emon' (such like), 'emoto' (in this manner), 'eimoto' (in this manner) etc. are used in Bengali.

In Assamese: - enekua:- enekua kam aru ketiyao nokoriba. [Don't repeat such type of work.]

In Bengali:- emoto:- emoto kaj aar kakhano karona.

[Don't repeat such type of work.]

In Assamese, prefix like $i$, is added in the root of direct demonstrative pronominal to indicate time, place, quantity. In Assamese, a pronominals like 'iman' (so much) is used to indicate quantity and in Bengali pronominals like 'eto' (so much) is used in a similar context, that is, to indicate quantity. As such, both the pronominals 'iman' and 'eto' are similar from the point of view of their meaning.

In Assamese:- iman:- iman ananda agote ketiau hua nai. [I have never been so happy earlier] 
In Bengali:- eto :- eto ananda aage kakhano hoyni. [I have never been so happy earlier]

Pronominals like 'iman' (so much), 'imanbor' (so many), 'imanbilak' (so many), 'imankhini' (so many) are used to demonstrate quantity in Assamese language. In this way in Bengali language, pronominals like 'etogulo' (so many), 'etogula' (so many), 'etoguli' (so many) are used.

In Assamese: - imankhini :- imankhini kamala nasta hoi gol. [So many oranges have destroyed.]

In Bengali: - etogulo:- etogulo kamala nasta hoye gelo.

[So many

oranges have destroyed.]

In Assamese, pronominal like 'iyat' (at this place), 'iyaloi' (to this place) are used to demonstrate any nearby place, and in Bengali language, pronominal like 'ekhane' (at this place), 'eikhane' (at this place) are used in a similar sense.

In Assamese: - iyat:- iyat akale akale ki korisa? [What are you doing all alone at this place?]

In Bengali: - ekhane:- ekhane eka eka ki korcho? [What are you doing all alone at this place?]

Like direct demonstrative pronominal, we can find similarities in respect of indirect demonstrative pronominal in both the languages. The prefix ' $t$ ' (from Table-1) expresses the sense of that, over there and is regarded as the distant demonstrative. (Goswami, 1982, p. 235). In Assamese language, pronominal like 'tetiya' (that time) and 'tahani' (long time since) are used to demonstrate any incident which took place at an earlier point of time. Similarly, in Bengali also, pronominal like 'oikhyan' (that time), 'takhan' (long time since) are used to demonstrate any incident which took place at an earlier point of time.

In Assamese: - tetiya:- tetiya sandhiya nami aahisil [At that time, the sun has already set.]
In Bengali: - oikhyan:- oikhyanei andhakar nemiye aslo [At that time, the sun has already set.]

In Assamese: - tahani:- tahanir dinot amar obastha khub beya asil. [In those days, our condition was very bad.]

In Bengali: - takhan:- takhan amar abastha khub kothin chilo. [In those days, our condition was very bad.]

In order to demonstrate similarity with a living creature or object in Assamese, pronominals like 'tene' (in that manner) 'tenekoi' (in the same manner) 'tenekua' (like that) and 'tenekuakoi' (in the same manner) are used. In Bengali, pronominals like 'amon' (like that), 'oimoto' (like that) and 'temon' (like that) are used in a similar context.

In Assamese: - tenekua:- tenekua kono kotha bhabar darker nai. [There is no need to think like that.]

In Bengali: - temon:- temon kichu kotha bhabar darker nei. [There is no need to think like that.]

In Assamese, pronominals like 'ximan' (so much) is used to demonstrate quantity, similarly in Bengali pronominal like 'ato' (so much) is used. In this way, in Assamese, pronominals like 'tat' (there), 'taloi' (to that place), 'tarpora' (from that place), 'teni' (in that direction) are used to demonstrate any place which is situated at a faroff place. In Bengali, pronominals like 'okhan' (there), 'okhane' (there), 'hotha' (there) are used to carry out the same meaning. From the point of view of the meaning of these pronominal, similarities among them are very apparent.

\section{Dissimilarities}

Like the similarities, the dissimilarities do exist in the use of demonstrative pronominal in both the language. The demonstrative pronominal having prefix ' $e$ ', like 'eo (he), 'eolok' (they), 'ekhetxakal' (they), 'eijoni' (this girl), 'eigoraki' (this lady) and having prefix ' $i$ ', like 'izona' (this person), 'izoni' (this girl), 'igoraki' (this lady) are used only in the Assamese language. Similarly, various pronominals are formed from the 
indirect demonstrative root of pronoun by using prefix ' $t$ ' and ' $x$ '. Some of these are like 'teo' (he), 'teolok' (they), 'tekhet' (he), 'tekhetxakal' (they), 'xeitu' (that person), 'xeijoni' (that girl). However, in Bengali, such types of pronominals are never used to demonstrate any person. Similarly, in Assamese, pronominals like 'eni' (this way)'eipine' (this way), 'xeipine' (that way), 'xeipinedi' (through that way), 'xouphale' (on that side), 'xithait' (on that place) are used to demonstrate any distant or near place, but, the same is not found in the Bengali language. On the other hand, several other pronominals viz.; 'ekhoni','ebe' are found only in Bengali to indicate the time which is again not used in the Assamese language.

\section{Relative Pronominal}

Relative pronominal always relate back to something or someone else. They are used to join two sentences about the same person or thing. In Assamese, various relative pronominals are formed from the root of pronominal having prefix ' $z$ ' (from Table-1). This is the morpheme for the derivation of the relative pronouns. In Bengali also, various relative pronominals are formed from the roots of pronominals having prefix ' $z$ ' (from Table-2) (Bhattacharyya, 1993; Morshed Manzur, 1985).

\section{Similarities}

In Assamese with respect to relative pronominals having prefix ' $z$ ', pronominals like 'ziman' (as much), 'zimanbor' (as much), 'zimanbilak' (as much) are found to represent quantity. In Bengali, the pronominals 'zoto' (as much) is used to mean the same.

In Assamese: - ziman:- zimankhini para loi jua. [Take away as much you can.]

In Bengali: - zoto:- zoto khini paro niye nao. [Take away as much you can.]

In order to represent time in Assamese, pronominal like 'zidina' (when), 'zetiya' (which time) are used. In Bengali, pronominals like 'zakhan' (when), 'zabe' (when) are used in a similar context.
In Assamese: - zetiya:- zetiya mur mon jabo moi tetiyai jam. [I will go whenever I want.]

In Bengali: - zakhan: - zakhan amar itcha hobe ami tokhonei jabo. [I will go whenever I want.]

In Assamese: - zidina: - zidina tumi ghuriba logote moiu ghurim [I will come back with you when you return.]

In Bengali: - zabe: - zabe tumi phiribe, sange amiu phiribo [I will come back with you when you return.]

In Assamese, pronominal like 'ziphale' (on which place), 'zithait' (on which place), 'zipinedi' (on which way) are used to denote any direction of any place. To convey the same meaning, pronominal like 'zekhan' (on that direction), 'zeikhane' (on that direction) is used in Bengali.

In Assamese: - ziphale: - ziphale khub bhir seiphale najaba. [Don't go to that direction where there is a crowd.]

In Bengali: - zeikhane: - zeikhane khub bhir seikhane jeyona.[Don't go to that direction where there is a crowd.]

In respect of relative pronominals, the other most important similarities between both the languages are that in Assamese pronominals which are used as similarly oriented pronominal like, 'zenekoi' (in the same manner as), 'zenekua' (like as), 'zenekuakoi' (in the same manner as) are similar in meaning with the pronominals like 'zemon' (in the same manner as), 'zemoto' (like as) used in Bengali. The similarity between both the languages is also seen in respect of pronominal in comparing two words. The use of such pronominal is very important to look into.

In Assamese: - zar-tar: - zar-tar kotha nuxusniba. [Don't listen to each and everyone.]

In Bengali: - zar-tar: - zar-tar kotha sunbena. [Don't listen to each and everyone.]

In Assamese: - zetiai-tetiai: - tar xamayar kono thik nai, zetiai-tetiai gusi ahe. [He 
comes at any time since he has no fixed time.]

In Bengali: - zakhan-takhan: - or samayer kono thik nei, zakhan-takhan sole ase. [He comes at any time since he has no fixed time.]

\section{Dissimilarities}

In respect of the use of relative pronominal, 'zitu' (who), 'zizan' (who), 'zigaraki' (who), 'zibor' (whose) are used to describe a person in the Assamese language, but the same are of no use in Bengali. In Bengali, a particular person is represented by using a relative pronoun. Similarly, describing a non-living object like 'zitu' (which), 'zikhan' (in which), 'zibor' (which) are of no use in Bengali.

\section{Conclusion}

The key purpose of this study was to examine a comparative analysis of the pronominals in Assamese and Bengali language. From the comparative analysis, . it can be stated that in respect of the use of pronominals in both the languages, various similarities as well as dissimilarities were found. Though it can be observed that in both the languages there are some distinct characteristics common with each other. Such use of pronominal having its distinct characteristics also offers separate and unique level to both the languages. From the comparative discussion of pronominals in both the languages following characteristics are found:

- Both similarities as well as dissimilarities, are found in respect of use of pronominal in both the languages which have developed parallelly. However, similarities outnumber dissimilarities. The main reason behind this is that the root of both the Assamese and Bengali language is the same, that is, Sanskrit.

- The pronominal which are found in both languages can be classified in the same manner. It is also found that among these pronominal, a large number of pronominals having similar meanings are found in both languages.
- In Assamese language, certain kinds of pronominals are found which have no use in the Bengali language. Though Assamese belongs to the Indo-Aryan language family but due to the impact of neighbouring nonAryan languages with which it has interacted for centuries, the language has emerged with certain distinct characteristics of its own. From the above, it is very much apparent that though both the languages have arisen out of the same root. However, very often, some dissimilarities also cropped up due to their independent linguisticcultural evolution over the ages.

From the above comparative study, it can be argued that as both the languages have developed in different geographical areas; therefore, between these two languages, separate characteristics are found. Nevertheless, despite all these, the variegated use of pronominal in both the languages have brought to light various aspects of their corelation with each other.

\section{References}

Akbulut, D.F. (2017). Effects of morphological awareness on second language vocabulary knowledge. Journal of Language and Linguistics Studies, 13 (1), 10-26.

https://www.jlls.org/index.php/jlls/article/view 1458

Bauer, L. (1983). English word formation. London: Cambridge University Press, 13-17.

Begum, J.A. (1982). Pronominal usage and appellatives in Bangla. Centre of Advanced Study in Linguistics Deccan College, 19-45.

Bhanot, T.R., \& Martin, H. (2013). Junior English grammar and composition. Ranade Group Company, 55-60.

Bhattacharya, B.K. (2008) Bhasa-vijnan prabesh. Chandra Prakash, 97-138.

Bhattacharyya, P. (1993). Bangla bhasa parikrama. Dey's Publishing.

Bhattacharyya, P.R. (2013). A pronominal system in Asamiya A descriptive study. (Unpublished doctoral thesis), Gauhati University, Guwahati, India. 
Bhattacharya, S. (2012). Bhasar tattwa o Bangla bhasa. Bangiya Sahitya Samsad, 81-88.

Bloomfield, L. (1963). Language. Foreign Language Teaching and Research Press, 217238.

Boruah, B.K. (2006). Tulanamulak bhasa adhyayan. Department of Assamese, Dibrugarh University, 1-14.

Chaetterji, S.K. (1970). The origin and development of the Bengali language. Rupa and Co. by arr. With London: George Allen 8 Unwin, 62-140.

Chatterji, S.K. (1988). Bhasha-prakash Bangla vyakaran. Rupa Publication India Limited.

Choudhury K.M. (2012). Bhashatatta Bangla bhashar itihas. Mandal Book House, 142-150.

Goswami, G. (1982). Structure of Assamese. Department of Publication Gauhati University, 236-238.

Goswami, G. (2004). Axomiya byakaranar moulik bichar. Bina Library, 99.

Goyal, S. (2020). 10 most Spoken Languages in India by Number of Speakers. Jagaran Josh. https://www.jagranjosh.com/generalknowledge/most-spoken-languages-in-india-bynumber-of-speakers-1541764100-1

Hazarika, L. (2006) Bhasabijnyan Aru Axamiya Bhasabijnyan Parichiti, Ashok Publications, 2697.

Kakoti, B. (1972). Assamese: Its formation and development. Lawyers Book Stall, 699-700.

Majumdar, P.C. (1980). Bangla bhasha parikrama. Dey's Publishing.

Morshed Manzur, A.K. (1985). Bangla sambandhabachak sarbanam gathan o prakriti. Bangla Academy.
Morshed Manzur, A.K. (2007). Adhunik

Bhasatatto. Naya Udyog, 334-338.

Nida, EA. (1949). Morphology. The University of Michigan, 1-5.

Office of the Registrar General \& Census Commissioner, India. (2011). Statement-1. https://censusindia.gov.in/2011Census/Langua ge-2011/Statement-1.pdf

Rabha Hakacham, U. (2000). Axomiya aru axomar tibbat-barmiya bhasa. Manjula Rabha Hakachamzak, 149-150.

Rabha Hakacham, U. (2009). Asamiya aru asamar Bhasa-Upabhasa. Jyoti Prakashan, 1-7.

Sengupta, S.B. (2013). Bangla bhasa: rupe proyoge. Dey's Publishing. 1-30.

\section{About the Author}

The author completed her Master degree in Assamese (Language) in the year 2009 under Gauhati University. Thereafter she did her B.Ed., in the year 2010. She has qualified UGC-NET for Junior Research Fellowship (JRF) and also completed her Ph.D. from Gauhati University in the year 2017. The author had served as a Guest Lecturer in Handique Girls' College and Lalit Chandra Bharali College, Guwahati. She is presently working as an Independent Researcher. The author has written many articles on various Research Journals, Books, Magazines etc. on various topics specially in the area of language study. Recently two articles were published in two UGC-CARE List journals, viz; "Dogo Rangsang" and "Sampriti".

\section{Acknowledgements}

The author is grateful to the two anonymous reviewers for the careful reading of her manuscript and their insightful comments and suggestions which have been significant in improving the manuscript of the paper. 